Canadian Journal of Family and Youth, 13(3), 2021, pp. 363- 370

ISSN 1718-9748@ University of Alberta

http://ejournals,library,ualberta.ca/index/php/cjfy

\title{
Advertising Leads to Consumerism in Children
}

\author{
Melania McNaught, MacEwan University
}

\section{Introduction}

The media is one of the major players influencing consumerism, particularly the advertising sector. Hayes (2021) defines consumerism as the tendency "to engage in a lifestyle of excessive materialism..." as consumption of goods and services is seen as a desirable goal fundamental to one's well-being and happiness. Advertisements are beneficial because they serve as a mode of promoting goods and services, however, the disadvantage of advertisements is that they aim to influence consumerist tendencies (Magatef \& Momani, 2020, p. 413). Today, ads are no longer limited to TV, newspapers, magazines, and street billboards, as they can be seen on various social media platforms, device applications, websites, and videogames, all of which are exposed to children in one way or another. Because children are perceived as vulnerable, advertisements are often geared towards them being the target audience. "Ads have a clear impact on children's purchasing behaviour as they create awareness and attention towards the advertised products...," ultimately turning this want into a need, especially when the characters used can convince the child of the qualities of the product (Magatef \& Momani, 2020, p. 412). It can be hypothesized that advertisements play a significant role in the influencing of consumerism in children.

\section{Children as The Target Audience for Advertisements}

With the revolution of communication and information, advertising serves as an indirect means of communication aimed to influence purchasing decisions (Magatef \& Momani, 2020). From a business standpoint, advertisements are necessary because they serve to promote goods and services. "Ads work to distribute advertising messages over consumers to encourage them to purchase goods or services" (Magatef \& Momani, 2020, p. 413). This is done by creating awareness of a particular product or service, persuading people into buying, and reminding potential buyers of the need for a product or service (Entreprenur.com, n.d). Companies spend billions of dollars per year on advertising alone. In 2020, Canada spent an estimated $\$ 10$ billion in advertising, a billion dollars short of what was spent in the two previous years (Statista, 2021). Given that the advertising sector is a money maker, businesses pool money into advertising and utilize marketing tactics to purposefully cater to children. 
On the one hand, this is because children are seen as an important market given, they have the ability to collect information, and be influenced by what they see, thus influencing parents' purchasing decisions. Marketers and businesses also see children today as "...capable of distinguishing between many advertised products" due to their intellectual and mental maturity (Magatef \& Momani, 2020, p. 411). On the other hand, Mehta and Bharadwaj (2021) assert that marketers target and take advantage of the fact that children are unable to process advertisements in the way adults can. Their limited vocabularies, language skills, and "...underdeveloped cognitive abilities often hinder their understanding of messages designed for a more mature television audience" (Mehta \& Bharadwaj, 2021, p. 2). Although children as young as 8 years old can understand the persuasive intent of advertising, they are unable to make use of this knowledge until they are older (Kennedy et al., 2019, p. 1479). Therefore, children are captivated by what is seen in ads and know no better than to want the product(s) presented, leading to consumerism which businesses benefit from. Chamberlain (2019) states that some marketers "...intentionally take advantage of young people's insecurities and their desire to fit in because advertisers only care about what is best for their bottom line, not what is best for kids."

According to The Australian Parenting Website (2019), children ages 0 to 2 cannot tell the difference between advertising and actual TV shows and programs. At around age 3 to 6 , though they are able to identify advertisements and distinguish them from TV shows and programs, they may not be able to distinguish between entertainment and advertising, and they "might not understand that advertisements are trying to sell something." Up until around age 7, children rely on the perceptual characteristics of advertising, then become increasingly analytical between ages 7 to 11 (Kennedy et al., 2019, pp. 1478-1479). Children in this age range can understand the selling factor of advertisements, can "remember advertising messages, and they can recognize persuasive techniques." However, they might not understand product value or the lack of and are quick to believe what is said about the product. By 13 years old, children are capable of understanding the purpose and persuasive intent behind advertisements despite not being able to recognize product placement strategies or that "clicking an advertisement on social media sends data to [marketers]" (Kennedy et al., 2019, p. 1478-1479). 14-year-olds and older may not know that social media platforms collect their data which is in turn used to target advertising to them, the users (The Australian Parenting Website, 2019). With marketers being aware of this, they take into consideration certain factors such as the message content of ads, frequency, the medium used, advertising times, and the characters used in the ads, which help to influence children's awareness and interest, thus prompting parents' response to purchase what is seen (Magatef \& Momani, 2020, p. 414). Often, ads targeted to children contain persuasive tactics like jingles, animations, and special characters used to beguile and attract.

\section{Accessibility to Advertisements}

Advertisements play a significant role in influencing consumerism in children because ads can be seen just about anywhere. "From commercials on television and radio, to advertisements placed in magazines...to product placements in television episodes, movies, and video games, advertising permeates all forms of media" (Bereska, 2018, p. 99). Nelson (2018) asserts that this 
is due to the contemporary media environment offering more opportunities for children's exposure to commercial messages (p. 303). Because advertisements can also be found "on billboards, the sides of public transit buses, bulletin boards... and even inside the doors of bathroom stalls," advertising itself can essentially be considered a form of media (Bereska, 2018, p. 99). According to Bereska (2018), in the 1970s, the average North American would encounter 500 advertisements per day. Today, advertisement exposure has increased tenfold, as more than 5,000 advertisements are seen daily, ranging up to 20,000.

Advertisements are especially prevalent in the lives of children today because they spend plenty of time on screens, and "where there are screens, there are ads" (Chamberlain, 2019). While television has been identified by Mehta and Bharadwaj (2021) as a powerful medium used as a tool for commercial persuasion (p. 1), other mediums have come to substitute the television, allowing for portability and mobility. Devices such as smartphones, tablets, and iPads offer large enough screens for children's viewing and can be taken anywhere. Children are sometimes left for hours to engage in games, watch shows and videos on these devices where they are being exposed to a wide range of advertisements. In a 2014 survey conducted with over 5,000 Canadian children in grades 4 through 11, Bereska (2018) details that approximately $25 \%$ of children in grade 4 had a personal cellphone or smartphone "and that proportion [increased] to more than $80 \%$ by grade 11." $75 \%$ of the children had a social networking profile or blog and reported YouTube and Facebook as their top two favourite social media platforms (p. 96), two of the most advertisementrich social networking sites.

Leetaru (2018) explains that social media platforms and gaming sites “...[sell] hypertargeted advertising based on algorithmically mining every second of their unwilling and unwitting users' lives." Advertisements seen are then filtered to be based on, linked, or related to frequently watched content or browsing history. Unknown to children that this is done intentionally by businesses to generate revenue, they fall into the trap of consumerism, and their parents are pulled into the trap as well. However, when it comes to accessibility to ads and children being the target market, ads involving products and services are not the only culprits. Currently, ads for gaming apps are also advertised, and with each download, businesses profit.

Washington (2010) reports that "the free nature of many apps is the single highest motivating factor driving app acquisition," so free content cannibalizes sales for businesses. Children feel inclined to download the eye-catching app advertised, and parents have no issue downloading it because it is free. When done, businesses profit from this. Advertisements can also be seen when using apps marketed as 'educational'. The glitz and glam in these advertisements intrigue children thereby influencing parents' purchasing decisions and consumerism. Consumer groups call for greater government regulation for children's apps as "advertisers are taking unfair advantage of young kids using apps" (CBC News, 2018).

\section{Advertising Works}

In a study conducted by Magatef and Momani (2020), deductive reasoning was used by way of qualitative research to see if commercial advertisements directed to children influence parents' purchasing decisions. They issued questionnaires to a simple random sample of Jordanian people living in the major cities of Irbid and Zarqa. The sample consisted of fathers and mothers 
between the ages of 20-51, ranging from one to seven children being in the household. Education level, wage, and employment status of the parents were some of the variables taken into consideration, along with the sex of the children in the household and family size. Through hypothesis testing, the researchers explored the direct effect of commercial ads on children, the effect of advertisements on parents' purchase decisions, and the direct effect of children on parents' purchase decisions. The three hypotheses were found positive, with statistically significant results that conclude that advertisements do indeed have an effect on children. Findings showed that "advertisement messages, frequency of ads, and means of advertising used has an effect on children's awareness." Likewise, ad messages, the time of the ad, and the means used to communicate the ad play a role in children's response (Magatef \& Momani, 2020, p. 419).

The administrative research approach explains this phenomenon. "Administrative research analyses the effects of media messages on individual's thoughts, feelings, and behaviours" (Bereska, 2018, p. 103). According to Bereska (2018), this micro-level approach holds individuals under a microscope to figure out and "determine what type of media messages will result in certain outcomes in individuals" (pp. 98-99). The administrative research approach finds that advertising works because of people's repeated exposure to advertisements. It allows them to recognize brands easier and "develop positive associations with those brands," thus giving them the urge to purchase the particular product or service (Bereska, 2018, p. 100) whether or not it is needed.

The effectiveness of advertising lies in persuasion. The ability to persuade people help change their attitudes about a particular product. "Research into the process of persuasion studies who says what to whom and with what effects." Findings show that the characteristics of the source of communication, the message itself, and the audience all impact the effectiveness of the attempt at persuasion (Bereska, 2018, p. 100). Bereska (2018, p. 101) says that marketers also make use of a subtle form of advertising known as product placement, which is the "inserting of brand-name products into television shows, movies, or video games". Product placement is not always done by marketers, however. Movie and show creators sometimes incorporate product placement in their projects. Nevertheless, this subtle form of advertisement also influences consumerism.

Other advertising techniques utilized by marketers include an appeal to emotion, repetition, statistics and data, endorsements, promotions and rewards, and special characters (GourmetAds.com, n.d.). Marketers and businesses also take into consideration certain factors such as the message content of ads in relation to the target audience, the number of times an ad is seen or heard, the medium used, time of day to advertise, and the characters used in the ads. These factors all help influence children's awareness and interest, which fosters consumerism (Magatef \& Momani, 2020, p. 414).

\section{Negative Effects of Advertising on Children}

One of the major negatives of advertisements is that it breeds consumerism, and consumerism sparks materialism. Nairn and Opree (2021) define materialism as the importance placed on possessions and their acquisitions "as a necessary or desirable form of conduct to reach desired end states, including happiness" (p. 162). Chamberlain (2019) states that from the constant stream of advertising, children learn that "buying more stuff leads to more happiness." Also, the more ads children see, the more materialistic they become, and there are consequences to these materialistic values. Eventually, children's level of materialism will be seen as “...the extent to 
which wealth and possessions are viewed as (1) central to their life, (2) an important source of happiness, and (3) a prominent means of judging their own success and that of others" (Nairn \& Opree, 2021, p. 162). In keeping with materialism, advertisements can influence certain clothes, toys, or other luxurious choices of a child. Chatterjee (2018) says this creates "brand consciousness and an affinity towards expensive branded items..." which may lead to children "[shunning] inexpensive things that serve the same purpose." Children may also feel persuaded to purchase a product they want, and when unable to do so, they may feel like this is a real problem when it is not.

Another negative of advertisements is that children often fall for the false imaging present in ads, end up believing the façade and lose touch with reality. Also, sometimes funny skits are incorporated in advertisements which may include inappropriate acts like lying and cheating (Chatterjee, 2018). Because children are vulnerable consumers "...unable to navigate the marketplace due to a lack of understanding, knowledge, and skills..." (Kennedy et al., 2019, p. 1480), and they fit the stereotype of being innocent and naïve, they imitate the inappropriate behaviour seen in advertisements thinking it is acceptable. Likewise, children may attempt the stunts seen in advertisements, especially in the absence of parents or guardians, despite the statutory warning saying not to do so (Chatterjee, 2018). Sexual objectification seen in some advertisements is also cause for concern, as children may grow up thinking this is the norm. Children might also interpret the overall message of advertisements in the wrong way, focusing on the negatives instead of the positives (Chatterjee, 2018). In addition to the above, advertisements create low self-esteem in children, especially those of a lower socio-economic class, making them feel inferior to their peers for not owning various highly-advertised and desired products (Chatterjee, 2018; Nairn \& Opree, 2021, p. 161).

However, advertising does not only affect the brains of children; it also harms their bodies (Chamberlain, 2019). Another adverse effect of advertisements on children has to do with foodrelated ads. Chamberlain (2019) reports that though visibly appealing, about $98 \%$ of food ads seen by children are for unhealthy foods, like soda, candy, and fast food. When children watch unhealthy food advertisements, they are inclined to eat unhealthy foods, leading to poor dietary practices and increasing their risk of health complications such as obesity and diabetes (Chamberlain, 2019; Chatterjee, 2018). Results from a multi-country study found that the rate of obesity was positively linked with the rate of exposure to food advertisements (Mehta \& Bharadwaj, 2021, p. 2). In a similar light, Mehta and Bharadwaj (2021) report the findings of an experimental study that showed a positive link between exposure to food advertisements and children's immediate consumption of unhealthy food (p. 2). This indicates that advertisements play a significant role in influencing consumerism in children to the point where it can impact their health.

\section{Suggestions and Possible Solutions}

Magatef and Momani (2020) see marketers as the ones to be held accountable for some of the advertisements catered to children, as the focus is only on profit-making, and to achieve this, they use children as targets because they consider them to be gullible and naïve (419). Mehta and Bharadwaj (2021) urge marketers to advertise products to children responsibly and be mindful of persuasive techniques used in advertisements (p. 2). Because of children's awareness level, it is 
recommended that marketers design a clear, honest, and convincing advertising message using various means of advertising (Magatef \& Momani, 2020, p. 419). There should also be limited use of characters or famous actors in ads as children are more "...keen to act the ads they are influenced by verbally or in the form of movements..." as a way to express themselves, which helps to pressure parents into making a purchase decision (Magatef \& Momani, 2020, 414). Businesses should also find other ways of advertising, such as in stores directly, through product placement on shelves, or locating products in particular places throughout the store. When it comes to food advertisements, Mehta and Bharadwaj (2021) suggest that children be provided with information about the nutrition or consumption value of the food being advertised as these are important attributes of the advertisement that can shape children's attitude toward food consumption (p. 2).

As a message to parents, The Australian Parenting Website (2019) suggests limiting screen time. Chatterjee (2018) says parents should download television programs or utilize advertisement-free streaming services like Netflix Kids, Disney+, and Hulu. If this cannot be done, parents should point out flaws in advertisements that they cannot shield children from, which will help the child develop critical judgment. As children grow, parents should initiate conversations with them about advertising and "encourage them to think about what they are trying to do...and the ways in which advertisements work to sell ideas [and] products" (The Australian Parenting Website, 2019). Parents must help children differentiate between 'needs' and 'wants,' initiate a conversation with them about why they want a particular product when asked to have it, teach children to only ask for things they need (Chatterjee, 2018), and last, stop this habit of giving in to buying things for children to shut them up or prevent them from crying.

\section{Conclusion}

Advertisements play a huge role in the influencing of children's consumerist tendencies. Children are more aware than we think, and though they may not fully understand the purpose or goal of advertisements, they are "vulnerable to advertising stimuli" (Mehta \& Bharadwaj, 2021, p. 1). Advertisements serve as business tactics, but they can generate emotions in children that can influence consumerism, thus pressuring parents into making rash and unnecessary purchasing decisions. Although movements and coalitions like Campaign for a Commercial-Free Childhood (C.C.F.C) are devoted to limiting the impact of commercial culture on children, ultimately, it is the job of parents to shield children from the guiles of advertising, to curb consumerism, and prevent the other negative effects that advertisements may have on children before it is too late. 


\section{References}

Bereska, T. (2018). Deviance, Conformity, and Social Control in Canada. (5 ${ }^{\text {th }}$ ed.). North York, Ontario: Pearson Canada Inc.

CBC News. (2018, October 31). 95 percent of most downloaded apps for young kids target them with ads, study finds. Retrieved from https://cbcnews.com/news/ads-targeting-childrengame-educational-apps/

Chamberlain, B. [The Story of Stuff Project]. (2019). How advertising rewires kids' brains. [Video]. YouTube. Retrieved from https://youtube.com/watch?v=hGN1ZEABk_Y

Chatterjee, T. (2018, January 23). Influence of Advertising on Children. Retrieved from https://parenting.firstcry.com/articles/effects-of-advertising-on-children/

Entrepreneur.com. (n.d.). Advertising. Retrieved from https://entrepreneur.com/encyclopedia/advertising

GourmetAds. (n.d.). Advertising Techniques. Retrieved from https://gourmetads.com/articles/advertising-techniques/

Hayes, A. (2021). Consumerism. Retrieved from https://investopesida.com/terms/c/consumerism.asp

Kennedy, A., Jones, K., Williams, J. (2019). Children as vulnerable consumers in online environments. Journal of Consumer Affairs, 53(4), 1478-1506. doi: 10.1111/joca.12253

Leetaru, K. (2018, December, 15). What does it mean for social media platforms to "sell" our data? Retrieved from https://forbes.com/sites/kalevleetaru/2018/12/15/what-does-itmean-for-social-media-platforms-to-sell-our-data/?sh=78c20a6e2d6c

Magatef, S., Momani, R. (2020). The role of commercial advertisements directed to children influencing on parents' purchasing decision. Management Science Letters, 10(2), 411-424. doi: 10.5267/j.msl.2019.8.029

Mehta, R., Bharadwaj, A. (2021). Food advertising targeting children in India: Analysis and implications. Journal of Retailing and Consumer Services, 59, 1-10. doi: 10.1016/j.jretconser.2020.102428

Nairn, A., Opree, S. (2021). TV adverts, materialism, and children's self-esteem: The role of socio-economic status. International Journal of Market Research, 63(2), 161-176. doi: $10.1177 / 1470785320970462$

Nelson, M. (2018). Research on children and advertising then and now: Challenges and opportunities for future research. Journal of Advertising, 47(4), 301-308.

doi: 10.1080/00913367.2018.1552218 
Statista. (2016). Media advertising revenue in Canada from 2012 to 2023. Retrieved from www.statista.com

The Australian Parenting Website. (2019, November 17). Advertising: How it influences children and teenagers. Retrieved from https://raisingchildren.net.au/toddlers/playlearning/screen-time-media/advertising-children

Washington, P. (2010, September 10). While the majority of mobile devices used by parents and kids have fewer than 20 apps for children, close to 10 percent have more than 60 . Retrieved from https://connectedworld.com/while-the-majortity-of-mobile-devices-usedby-parents-and-kids-have-fewer-than-20-apps-for-children-close-to-10-percent-havemore-than-60/ 